\title{
Bites and stings from venomous animals: a neglected Brazilian tropical disease
}

\author{
Palmira Cupo ${ }^{[1],[2]}$
}

\begin{abstract}
[1]. Departamento de Puericultura e Pediatria, Faculdade de Medicina de Ribeirão Preto, Universidade de São Paulo, Ribeirão Preto, São Paulo, Brasil. [2]. Centro
\end{abstract} de Controle de Intoxicações, Unidade de Emergência do Hospital das Clínicas, Faculdade de Medicina de Ribeirão Preto, Ribeirão Preto, São Paulo, Brasil.

Snakebites represent a public health and environmental problem that mainly affects the rural communities of poor and developing countries in Africa, Asia, Latin America, and Oceania. The most affected groups are rural workers, especially men, and snakebites are often characterized as occupational hazards for these groups. The children of rural workers are often victims as well(1).

The true impact of snake envenoming is concealed by the absence of reliable data regarding the epidemiology of this problem, practically across the world. However, the considerably difficulty of obtaining these data should be kept in mind; in addition to failures of notification, many patients do not seek medical care at all, or are treated and then transferred elsewhere, rendering them invisible to the health system. Another important and little-known problem is the impact of the anatomical and functional sequelae that can be induced by these bites. Although the number of these sequelae occurrences is unknown, it is estimated to be much higher than the number of deaths ${ }^{(2)}$. The compulsory notification of snakebites is definitely a positive contributor to the improvement of information, but great efforts are required at the local, regional, and national levels for this purpose.

Chippaux ${ }^{(3)}$ has estimated that there are $5,400,000$ snakebites per year worldwide, as well as 2,500,000 envenoming episodes and 125,000 deaths ${ }^{(2)}$. Using a different methodology, Kasturiratne et al. ${ }^{(4)}$ have estimated that there are 421,000 to $1,841,000$ envenomings per year worldwide, as well as 20,000 to 94,000 deaths. The number of sequelae was estimated to be $250,000^{(2)}$. The largest numbers of bites occur in Asia, South and Southeast Africa, and Central and South America. The mortality rates in these regions are high because it is difficult to obtain rapid access to health services, which are not always well equipped, and because antivenoms (AVs) are scarce. However, despite the alarming international data, snakebites have received little attention from governments, research agencies, and health agencies.

Corresponding author: Dra. Palmira Cupo. Depto. de Puericultura e Pediatria/HC/ FMRPUSP. Av. Bandeirantes 3900, 14049-900 Ribeirão Preto, São Paulo, Brasil. Phone: 55 16 3620-2772; 55 16 3620-1194

e-mail: pcupo@fmrp.usp.br

Received 11 November 2015

Accepted 24 November 2015
In January 2007, a consultantship meeting was held in Geneva, Switzerland, under the auspices of the World Health Organization (WHO) regarding the production of heterologous sera. The meeting generated a publication entitled, Rabies and Envenomings - A Neglected Public Health Issue ${ }^{(1)}$ in which venomous animals (specifically snakes and scorpions) were considered to be a neglected public health problem. The term neglected disease dates back to the decade of the 1970's and refers to diseases caused by infectious and parasitic agents that tend to be endemic in low-income groups who live in rural zones, inappropriate dwellings, conditions of deficient sanitation, and tropical and developing countries in Africa, Asia, and the Americas. The term neglected refers both to the fact that these diseases do not attract the interest of large pharmaceutical companies for the production of medications and vaccines, and to the fact that research in this sector is reliant on insufficient resources ${ }^{(1)}$.

In 2008, a project called the Global Snakebite Initiative was launched in Melbourne, Australia, with the support of the International Society of Toxinology, which has subsequently suggested guidelines for viable solutions to snakebite-related problems ${ }^{(5)}$.

In 2009, a study that surveyed the available global data on mortality caused by snakebites and socioeconomic indicators of poverty clearly demonstrated a negative association between deaths due to snakebites and countries with governmentsupported health expenditures ${ }^{(6)}$. In the same year, snake envenomings were included in the WHO's list of Neglected Tropical Diseases, although bites by venomous animals are not listed in more recent publications about this subject.

Although snakebites do not have the epidemic potential of infectious diseases and vector-mediated parasitic diseases, it should be emphasized that the annual mortality caused by these envenomings is much higher than that attributed to various diseases considered to be neglected, such as hemorrhagic dengue, cholera, leishmaniosis, schistosomiasis, and Chagas disease, among others ${ }^{(5)}$. The impact of snakebites continues to be invisible and is not treated as a critical public health problem. Even though snakebite is considered to be a neglected condition, there have not been any control or prevention programs associated with the WHO to date.

During the most recent decade, several strategies have been implemented to reduce the impact of neglected diseases in 
accordance with the Millennium Development Goals (MDGs), which were established by the United Nations and incentivized by the WHO, governments health organizations, support agencies, and foundations ${ }^{(7)}$. Unfortunately, snakebites were not included in the projects that were designed to reduce the impact of neglected diseases, perhaps because snakebite is not an infectious disease, and it is therefore believed that snakebiterelated public health burdens would not benefit from the same strategies that are used to combat infections. For example, it is not possible to eradicate snakes, even though it is possible to eradicate many vectors that cause most neglected diseases.

The most serious and troubling problem regarding snakebites is that the treatment (i.e., AV) already exists and is often highly effective if it is applied in a timely and correct manner. In addition, AVs are part of the WHO's list of essential medications $^{(7)}$, and should therefore be available in all regions where snakebites occur (although this is not always the case in practice). The production of, distribution of, and free access to effective AV should be the right of all citizens without discrimination, especially those who are more vulnerable and marginalized. However, not all countries and regions have access to AV or even to its production, especially Africa and Asian regions. In addition, AV is of no value if health professionals do not have the knowledge and training that are necessary to treat victims correctly. It should be pointed out that this subject is not included in most medical, nursing, or pharmacy curricula, and that there is a lack of continuing education programs for health professionals.

In Brazil, the National Program for the Control of Snakebites was instituted in 1986 and, since 1988, has been extended to envenomings by other poisonous animals. AV production has been standardized since then, and the Ministry of Health distributes the entire production of the three national laboratories (Ezequiel Dias Foundation, Butantan Institute, and Vital Brasil Institute) to all health institutions free-of-charge, to allow patients to be treated ${ }^{(8)}$. Nevertheless, access to AV in a timely manner is still difficult in many regions in the north of the country.

According to the Ministry of Health, 171,213 episodes of envenomings by poisonous animals were registered in Brazil in 2014, of which 88,246 were attributed to scorpions, 27,183 were attributed to snakes, 27,103 were attributed to spiders, 14,173 were attributed to bees, and 3,529 were attributed to caterpillars $^{(9)}$. It can be seen that, today, scorpion stings are three times more frequent than snakebites, an increase that has been occurring since 2004. Indeed, all envenomings due to venomous animals should be included in the WHO's list of neglected diseases, and thus receive more attention in public health policies worldwide.

According to Gutierrez et al. ${ }^{(2)}$ facing the problem of snakebites requires a multifocal approach that can cope with complex problems and involves many participants, including the components described below:

1. Obtaining reliable information about the incidence and mortality attributable to snake envenomings and the number of persons with permanent sequelae.
2. Improving the production of effective and safe AV using strategies that will reinforce the technological capacity of the laboratories that produce AV.

3. Increasing the capacity of low-income regions to extract venom from snakes and to perform their own quality control.

4. Convincing regional producers to produce $\mathrm{AV}$ for countries where this production is not yet possible.

5. Implementing initiatives that will guarantee the acquisition of appropriate $\mathrm{AV}$ volumes at accessible prices by lowincome countries.

6. Performing collaborative studies of the safety and efficacy of $\mathrm{AV}$ in preclinical trials and in clinical designs.

7. Developing a program of AV distribution adapted to the real necessities and epidemiological situations of rural areas in each country.

8. Developing programs of permanent continued education for health professionals, particularly in rural areas where the bites are more frequent.

9. Implementing programs of support for victims of snakebites who have become chronically incapacitated.

10. Establishing preventive and educational community programs with the active involvement of local organizations and using modern methods of health promotion.

Only with these integrated global approaches will it be definitively possible to reduce the human suffering that is caused by the bites and stings of venomous animals. As Bill Gates has stated ${ }^{(5)}(10)$, Humanity's greatest advances are not in its discoveries - but in how those discoveries are applied to reduce inequity. Whether through democracy, strong public education, quality health care, or broad economic opportunity - reducing inequity is the highest human achievement.

\section{CONFLICT OF INTEREST}

The authors declare that there is no conflict of interest.

\section{REFERENCES}

1. World Health Organization (WHO). Rabies and envenomings. A neglected public health issue. Geneva: WHO; 2007.

2. Gutiérrez JM, Williams D, Fan WH, Warrell DA. Snakebite envenoming from a global perspective: Towards an integrated approach. Toxicon 2010; 56:1223-1235.

3. Chippaux JP. Snake-bites: Appraisal of the global situation. Bull World Health Organ 1998; 76:515-524.

4. Kasturiratne A, Wickremasinghe AR, de Silva N, Gunawardena, NK, Pathmeswaran A, Premaratna R, et al. The Global Burden of Snakebite: a Literature Analysis and Modeling Based on Regional Estimates of Envenoming and Deaths. PLoS Med 2008; 5:e218.

5. Williams D, Gutiérrez JM, Harrison R, Warrell DA, White J, Winkel KD, et al. The Global Snake Bite Initiative: an antidote for snake bite. Lancet 2010; 375:89-91.

6. Harrison RA, Hargreaves A, Wagstaff SC, Faragher B, Lalloo DG. Snakebite envenoming: a disease of poverty. PLoS Negl Trop Dis 2009; 3:e569. 
7. Gutiérrez JM, Warrell DA, Williams DJ, Jensen S, Brown N, Calvete JJ, et al. Global Snakebite Initiative. The need for full integration of snakebite envenoming within a global strategy to combat the neglected tropical diseases: the way forward. PLoS Negl Trop Dis 2013; 7:e2162.

8. Wen FH, Monteiro WM, Moura da Silva AM, Tambourgi DV, Mendonça da Silva I, Sampaio VS, et al. Snakebites and Scorpion Stings in the Brazilian Amazon: Identifying Research Priorities for a Largely Neglected Problem. PLoS Negl Trop Dis 2015; 9:e0003701.
9. Ministério da Saúde (MS), Secretaria de Vigilância em Saúde. Sistema de Informação de Agravos de Notificação (SINAN). Acidentes por Animais Peçonhentos (Internet). Brasília: MS; 2004. (Acessed 2015 November 11). Available at http://dtr2004. saude.gov.br/sinanweb/tabnet/dh?sinan/animaisp/bases/animaisbr.

10. Gates B. Remarks of Bill Gates. Harvard University commencement speech. Cambridge: Harvard University Gazette Online 2007. Available at http://news.harvard.edu/gazette/story/2007/06/remarksof-bill-gates-harvard-commencement-2007/ 